\title{
Identifying the gaps between science, policies, services, and the needs of youths affected by mental disorders
}

\author{
Guilherme V. Polanczyk
}

Published online: 23 November 2014

(C) Springer-Verlag Berlin Heidelberg 2014

Mental disorders are estimated to affect 10-20\% of children and adolescents around the world and are major causes of morbidity among youth [10]. Evidence from different countries suggests that the number of youths with reported diagnoses of mental disorders in the community has increased substantially during the past decades [1, 17], although there is no evidence to indicate that the actual prevalence of disorders has increased [12]. Surprisingly, despite the fact that mental disorders have been increasingly recognized by professionals and the community, associated morbidity and mortality have remained stable [3].

There are several possible explanations to explain why increasing rates of diagnoses do not translate into broad benefits to the health of the population. First, although rates of diagnoses have increased over time, the absolute number of youths affected by disorders who did not receive a diagnosis or treatment is still large. This is the case in the National Comorbidity Survey Adolescent Supplement (NCS-A) study, a nationally representative survey of adolescents from the US. Among those with any diagnosis, $45 \%$ reported receiving any treatment from any source [4] and $14.2 \%$ reported that they had been treated with a medication [6], both in the past 12 months.

G. V. Polanczyk ( $\bowtie)$

Department of Psychiatry, University of São Paulo Medical School, São Paulo, Brazil

e-mail: gvp@usp.br

\section{G. V. Polanczyk}

National Institute of Developmental Psychiatry for Children and Adolescents (INCT-CNPq), São Paulo, Brazil

G. V. Polanczyk

Research Support Center on Neurodevelopment and Mental

Health, University of São Paulo, São Paulo, Brazil
Second, there is a lack of solid empirical evidence for the treatment of a variety of conditions, and frequently the available evidence is not incorporated by the health systems [10]. The gap between interventions that are available in community settings and interventions that are evidence-based is even larger in low-resource settings [11]. Pharmacological interventions are commonly preferred because they are more easily delivered, with high fidelity if adherence is good. However, attributes of medications and patients' and families' preferences are usually not addressed by clinicians and have important implications on adherence [7]. On the other hand, psychotherapeutic approaches available in the health system usually lack consistency and are directed by the professional's theoretical affiliation, not by patient needs. Also, treatments are frequently delivered by professionals with limited training in inadequate formats. For example, nationally representative survey data from visits to office-based physicians in the US revealed that visits with a prescription of antipsychotic medications per 100 persons increased from 0.24 to 1.83 for children and $0.78-3.76$ for adolescents between 1993-1998 and 2005-2009 [8]. Only $6 \%$ of children and $12.7 \%$ of adolescents' antipsychotic visits included a FDA clinical indication, and disruptive behavior disorders were the diagnosis for 63 and $33.7 \%$ of visits for children and adolescents, respectively, despite the limited evidence for this indication and the urgent need of short- and long-term studies assessing its efficacy and safety, as addressed by the article from the Paediatric European Risperidone Studies Consortium in this issue [16]. Noteworthy, mean duration of antipsychotic visits was approximately $25 \mathrm{~min}$ and only approximately $30 \%$ of them included psychotherapy [8], despite solid evidence on the efficacy of psychosocial interventions for several mental disorders, such as disruptive behavior disorders, for example in [15]. Children aged 2-5 years have also been 
increasingly treated with antipsychotics [9]. Nevertheless, only approximately $40 \%$ of them received a mental health assessment, a psychotherapy visit, or a visit with a psychiatrist during the year of antipsychotic use [9]. In Canada, rates of antipsychotic indication for children also increased, by $114 \%$ from 2005 to 2009 , while indications for stimulants and antidepressants increased by 36 and $44 \%$, respectively. Attention-deficit/hyperactivity disorder was the most common indication for antipsychotic use [14]. In Denmark, data on filled selective serotonin reuptake inhibitors obtained for all children aged 5-17 during 1995-2011 demonstrated that prevalence proportion rose from 0.1 per 1,000 children in 1995 to 3.3 in 2011. However, about $50 \%$ of adolescents and $40 \%$ of children discontinued treatment within 12 months of initiation [13].

Third, the science produced to date has focused almost exclusively on behavioral manifestations of disorders and failed to uncover etiological factors, early neurodevelopmental deviations, and trajectories to disorders [5]. Therefore, current treatments target overt symptoms, but do not promote cure, leading to disappointment and a general lack of confidence on the discipline. Misconceptions, stigma, and concerns about over-diagnosis and over-treatment are likely important barriers to adequate treatment and are related to the failure of the scientific community to understand and communicate consolidated knowledge about mental disorders. It is clear that understanding normal and deviant human brain development in the context of the environment across time is not a simple task. Nevertheless, it is now clear that new questions and approaches are urgently needed [5].

Finally, related to all aspects addressed above, there is a lack of child and adolescent mental health policies across the globe. The Atlas project identified only $7.0 \%$ of countries (14 of 191) with a clearly articulated specific (standalone) child and adolescent mental health policy in 2002 [2]. Important contrasts exist between world regions. In Europe and in the WHO African Region, for example, 95.8 and $33.3 \%$ of countries had some form of child and adolescent mental health policy, and 66.7 and $6.3 \%$ of countries an identifiable child and adolescent mental health program, respectively [2]. Also, policies are frequently influenced by ideologies and not science. For example, the city of São Paulo, Brazil, which has the largest economy in Latin America and the southern hemisphere, does provide methylphenidate for children only after a panel of non-medical professionals (e.g., speech and occupational therapists, social workers, psychologists, nurses) revise and approve a detailed medical report supporting its indication for every child, which should be renewed every 6 months. Strict (and not supported by scientific evidence) criteria are followed to approve the indication; for example, the presence of anxiety or mood disorders is considered as a contra-indication to the use of this medication. The rationale for this procedure is that "medication therapies weaken psychotherapeutic interventions". However, the city's health system does not offer any kind of evidence-based non-pharmacological intervention to treat children with ADHD.

There are clearly important gaps between science, policies, services, and the needs of youths affected by mental disorders. No single action will be enough to fill all these gaps, and coordinated movements are needed to address each one of them. The National Institute of Mental Health Research Domain Criteria and the Grand Challenges in Global Mental Health are important examples of such initiatives. It is imperative that scientists and clinicians identify how their individual actions can address the needs of the population by filling specific gaps in the context of coordinated movements.

Conflict of interest Prof. Polanczyk is employed by the University of São Paulo. He receives research support from the National Council for Scientific and Technological Development (CNPq) [Bolsa de Produtividade em Pesquisa], the São Paulo Research Foundation (FAPESP), and the University of São Paulo. He has served as a consultant to Shire. He has served on the speakers' bureau of Shire. He has received royalties from Editora Manole.

\section{References}

1. Atladottir HO, Gyllenberg D, Langridge A, Sandin S, Hansen SN, Leonard H et al (2014) The increasing prevalence of reported diagnoses of childhood psychiatric disorders: a descriptive multinational comparison. Eur Child Adolesc Psychiatry. doi:10.1007/ s00787-014-0553-8

2. Belfer ML (2007) Critical review of world policies for mental healthcare for children and adolescents. Curr Opin Psychiatry 20(4):349-352. doi:10.1097/YCO.0b013e3281bc0cf4

3. Collins PY, Patel V, Joestl SS, March D, Insel TR, Daar AS et al (2011) Grand challenges in global mental health. Nature 475(7354):27-30. doi:10.1038/475027a

4. Costello EJ, He J-P, Sampson NA, Kessler RC, Merikangas KR (2014) Services for adolescents with psychiatric disorders: 12-month data from the National Comorbidity Survey-Adolescent. Psychiatric Serv (Washington, DC) 65(3):359. doi:10.1176/appi.ps.201100518

5. Insel TR (2014) Mental disorders in childhood: shifting the focus from behavioral symptoms to neurodevelopmental trajectories. JAMA 311(17): 1727-1728

6. Merikangas KR, He J-P, Rapoport J, Vitiello B, Olfson M (2013) Medication use in US youth with mental disorders. JAMA Pediatrics 167(2):141. doi:10.1001/jamapediatrics.2013.431

7. Nafees B, Setyawan J, Lloyd A, Ali S, Hearn S, Sasane R et al (2014) Parent preferences regarding stimulant therapies for ADHD: a comparison across six European countries. Eur Child Adolesc Psychiatry. doi:10.1007/s00787-013-0515-6

8. Olfson M, Blanco C, Liu S-M, Wang S, Correll CU (2012) National trends in the office-based treatment of children, adolescents, and adults with antipsychotics. Arch Gen Psychiatry 69(12):1247-1256. doi:10.1001/archgenpsychiatry.2012.647

9. Olfson M, Crystal S, Huang C, Gerhard T (2010) Trends in antipsychotic drug use by very young, privately insured children. J Am Acad Child Adolesc Psychiatry 49(1):13-23. doi:10.1016/j.jaac.2009.09.003 
10. Patel V, Flisher AJ, Hetrick S, McGorry P (2007) Mental health of young people: a global public-health challenge. Lancet 369(9569):1302-1313. doi:10.1016/S0140-6736(07)60368-7

11. Patel V, Kieling C, Maulik PK, Divan G (2013) Improving access to care for children with mental disorders: a global perspective. Arch Dis Child 98(5):323-327. doi:10.1136/archdisch ild-2012-302079

12. Polanczyk GV, Willcutt EG, Salum GA, Kieling C, Rohde LA (2014) ADHD prevalence estimates across three decades: an updated systematic review and meta-regression analysis. Int $\mathbf{J}$ Epidemiol. doi:10.1093/ije/dyt261

13. Pottegård A, Zoëga H, Hallas J, Damkier P (2014) Use of SSRIs among Danish children: a nationwide study. Eur Child Adolesc Psychiatry. doi:10.1007/s00787-014-0523-1

14. Pringsheim T, Lam D, Patten SB (2011) The pharmacoepidemiology of antipsychotic medications for Canadian children and adolescents: 2005-2009. J Child Adolesc Psychopharmacol 21(6):537-543. doi:10.1089/cap.2010.0145

15. Tarver J, Daley D, Lockwood J, Sayal K (2014) Are self-directed parenting interventions sufficient for externalising behaviour problems in childhood? A systematic review and meta-analysis. Eur Child Adolesc Psychiatry. doi:10.1007/s00787-014-0556-5

16. The PERS Consortium, Glennon J, Purper-Ouakil D, Bakker M, Zuddas A, Hoekstra P et al (2013) Paediatric European Risperidone Studies (PERS): context, rationale, objectives, strategy, and challenges. Eur Child Adolesc Psychiatry. doi:10.1007/ s00787-013-0498-3

17. Visser SN, Danielson M, Bitsko RH, Holbrook JR, Kogan MD, Ghandour RM et al (2013) Trends in the parent-report of health care provider-diagnosed and medicated attention-deficit/hyperactivity disorder: United States, 2003-2011. J Am Acad Child Adolesc Psychiatry 53(1):34-46.e2. doi:10.1016/j.jaac.2013.09.001 